\title{
A novel TREM2 splice isoform lacking the ligand binding is expressed in brain and shares localization
}

\author{
Benjamin C. Shaw ${ }^{\text {a† }}$, Henry C. Snider ${ }^{\text {a† }}$, Andrew K. Turner ${ }^{\mathrm{a}}$, Diana J.
}

Zajac $^{\mathrm{a}}$, James F. Simpson ${ }^{\mathrm{a}}$, Steven Estus ${ }^{\mathrm{a}^{*}}$

${ }^{a}$ Department of Physiology and Sanders-Brown Center on Aging, University of Kentucky, 789 S

Limestone St., Lexington, KY 40536.

$\dagger$ These authors contributed equally to this work

Running Title: Novel TREM2 isoforms in Alzheimer's brain

Correspondence to:

Steve Estus, PhD

Sanders-Brown Center on Aging, Room 537

789 S. Limestone St,

Lexington, KY 40536

Phone: 859-218-2388

e-mail: steve.estus@uky.edu 


\title{
A novel TREM2 splice isoform lacking the ligand binding is expressed in brain and shares localization
}

\begin{abstract}
Background: Genetic variants in TREM2 are strongly associated with Alzheimer's Disease $(A D)$ risk but alternative splicing in TREM2 transcripts has not been comprehensively described.

Objective: Recognizing that alternative splice variants can result in reduced gene expression and/or altered function, we sought to fully characterize splice variation in TREM2.
\end{abstract}

Methods: Human blood and anterior cingulate autopsy tissue from 61 donors were used for genotyping and cDNA synthesis followed by both end-point and quantitative PCR to identify and quantify novel TREM2 isoforms.

Results: In addition to previously described transcripts lacking exon 3 or exon 4, or retaining part of intron 3, we identified novel isoforms lacking exon 2, along with isoforms lacking multiple exons. Isoforms lacking exon 2 were predominant at approximately $10 \%$ of TREM2 mRNA in the brain. Expression of TREM2 and frequency of exon 2 skipping did not differ between AD samples and non-AD controls $(p=0.1268$ and $p=0.4909$, respectively). Further, these novel splice isoforms were also observed across multiple tissues with similar frequency (range 5.3 - 13.0\%). Using ectopic expression, we found that the exon 2 skipped isoform D2-TREM2 is translated to protein and localizes similarly to full-length TREM2 protein, and that both proteins are primarily retained in the Golgi complex.

Conclusion: Since the TREM2 ligand binding domain is encoded by exon 2, and skipping this exon retains reading frame while conserving localization, we hypothesize that $D 2$ - 
bioRxiv preprint doi: https://doi.org/10.1101/2021.11.23.469712; this version posted November 23, 2021. The copyright holder for this preprint (which was not certified by peer review) is the author/funder, who has granted bioRxiv a license to display the preprint in perpetuity. It is made available under aCC-BY-NC-ND 4.0 International license.

TREM2 acts as an inhibitor of TREM2 and that targeting TREM2 splicing may be a novel therapeutic pathway for AD.

Keywords: Alzheimer's Disease, alternative splicing, gene expression, colocalization. 


\section{Introduction}

TREM2 is an activating receptor expressed on innate immune cells, and genetic variants in the TREM2 gene are associated with both Nasu-Hakola disease and Alzheimer's Disease (AD) [1-3]. Genome-wide association studies (GWAS) have confirmed that variants rs75932628 and rs 143332484, encoding the p.R47H and p. $\mathrm{R} 62 \mathrm{H}$ variants, respectively, in TREM2 are strong risk factors for developing late-onset AD (LOAD) [4-7]. These variants reduce TREM2 function [8-11]. TREM2 is a receptor for both Apolipoprotein E (ApoE) [12] and amyloid beta $(A \beta)[13]$, and regulates $A \beta$ phagocytosis [10,13,14], transcriptional changes [15], and microglial transition to a full disease-associated phenotype [16]. Murine models of AD suggest TREM2 may be beneficial early in the disease but detrimental later; Trem2 $2^{K O}$ or Trem2 $2^{R 47 H}$ mice crossed with amyloid-based AD models (APP/PS1 or 5xFAD mice) develop greater A $\beta$ pathology [17, 18], but when crossed with the PS19 humantau-model, reduced tau pathology [9, 19].

TREM2 is a five-exon gene that has been reported to undergo alternative splicing [2022], wherein exon 3 (D3-TREM2) or exon 4 (D4-TREM2) are skipped, or exon 4 is extended to a include a 3' portion of intron 3. Each of these three alternative splicing isoforms results in a frameshift mutation; exon 3 skipped has been associated with Nasu-Hakola disease as well [21, 22]. Interestingly, though both isoforms encode proteins which lack a transmembrane domain and are expected to be secreted, the exon 4 variants have not been reported as associated with Nasu-Hakola disease possibly due to the lack of an identified causal genetic variant for this isoform. Modulation of TREM2 splicing has been proposed as a potential therapeutic for NasuHakola disease previously [21], similar to the recent successes with spinal muscular atrophy [23]. Further TREM2 splice variants had not been reported until very recently [24], when an isoform lacking exon 2 (D2-TREM2), which encodes the ligand binding domain, was identified. 
This D2-TREM2 isoform maintains the reading frame and transmembrane domain but lacks the ligand binding domain.

In this study, we sought to fully characterize TREM2 alternative splicing in brain. We identify many more alternative splice isoforms than previously reported, and report that this alternative splicing is not brain-specific as it is conserved across multiple tissues. Further, we show that the D2-TREM2 splice isoform is translated into protein using overexpression paradigms, and that this D2-TREM2 protein has similar compartment localization as the fulllength (FL-TREM2) protein. We propose that modulating D2-TREM2 could be exploited to enhance TREM2 function-by decreasing D2-TREM2 early, one could increase the thenbeneficial functional TREM2; by increasing D2-TREM2 late in disease, one could inhibit the then-detrimental functional TREM2. 


\section{Materials and Methods}

\section{Preparation of DNA, RNA, and cDNA from human samples}

Human blood and anterior cingulate autopsy tissue from 61 donors were generously provided by the Sanders-Brown Alzheimer's Disease Center neuropathology core and their characteristics and cDNA synthesis have been described elsewhere [38]. All human subjects research was carried out in accordance with the University of Kentucky Institutional Review Board under protocol number 48095. The matched brain and blood samples were from deceased individuals with an average age at death of $82.4 \pm 8.7$ (mean $\pm S D$ ) years for non-AD and $81.7 \pm 6.2$ years for $A D$ subjects. The average postmortem interval (PMI) for non-AD and AD subjects was $2.8 \pm 0.8$ and $3.4 \pm 0.6$ hrs, respectively. Non-AD and AD samples were comprised of $48 \%$ and $55 \%$ female subjects, respectively. MMSE scores were, on average, $28.4 \pm 1.6$ for non-AD subjects and $11.9 \pm 8.0$ for AD subjects. Total RNA was prepared using a Qiagen RNeasy Lipid Tissue Mini kit (Qiagen \#74804) according to manufacturer's instructions. Reverse transcription was carried out using SuperScript IV (Invitrogen \#18091050) according to manufacturer's instructions. For cross-tissue splicing comparison, fetal RNA libraries from various tissues were obtained from a commercial vendor (Stratagene) and their cDNA preparation has been described elsewhere [39].

\section{Cell Culture}

The HMC3 human microglial cell line was obtained from American Type Culture Collection (ATCC CRL-3304). Cells were cultured in Eagle's Modified Minimum Essential Medium (EMEM), ATCC modification (ATCC 30-2003) supplemented with $10 \%$ fetal bovine serum, defined (HyClone, GE Healthcare SH30070.03); $50 \mathrm{U} / \mathrm{mL}$ penicillin, $50 \mu \mathrm{g} / \mathrm{mL}$ streptomycin (Gibco 22400-089). Cells were maintained at $37^{\circ} \mathrm{C}$ in a $5 \% \mathrm{CO}_{2}$ in air atmosphere. 
The cDNA samples from the anterior cingulate samples were amplified using primers corresponding to TREM2 exon 1 (5'-CCTGACATGCCTGATCCTCT-3') and exon 5 (5'GTGTTCTTACCACCTCCCC-3') with Q5 high-fidelity hot-start polymerase (NEB \# M0493L). Thermocylcing parameters were as follows: $98^{\circ} \mathrm{C} 30 \mathrm{~s} ; 98^{\circ} \mathrm{C} 5 \mathrm{~s}, 67^{\circ} \mathrm{C} 5 \mathrm{~s}, 72^{\circ} \mathrm{C} 45 \mathrm{~s}, 30$ cycles; $72^{\circ} \mathrm{C} 2 \mathrm{~min}, 25^{\circ} \mathrm{C}$ hold. PCR products were separated on a $8 \%$ acrylamide gel and imaged using a BioRad ChemiDoc XR. Bands were extracted for subsequent amplification as above and purification using a Monarch PCR Cleanup Kit (NEB T1030L). Purified products were sequenced commercially (ACGT; Wheeling, IL) and compared to the reference transcript NM_018965.4 to determine splicing.

\section{Quantifcation of TREM2 transcripts}

Quantitative PCR (qPCR) was used to quantify expression of TREM2 transcripts. Primers corresponding to sequences within exons 1 and 2 were used to quantify TREM2 exon 2 expression (forward, 5'-CCTTGGCTGGGGAAGGG-3'; reverse, 5'-

TCATAGGGGCAAGACACCTG-3'), as well as primers corresponding to sequences at the exon 1-3 junction and within exon 3 to quantify the D2-TREM2 isoform (forward, 5'-

TTACTCTTTGTCACAGACCCC-3'; reverse, 5'-GGGCATCCTCGAAGCTCT-3'). PCR was conducted using an initial 2 min incubation at $95^{\circ}$, followed by 40 cycles of $10 \mathrm{~s}$ at $95^{\circ} \mathrm{C}, 20 \mathrm{~s}$ at $60^{\circ} \mathrm{C}$, and $20 \mathrm{~s}$ at $72^{\circ} \mathrm{C}$. The $20 \mu \mathrm{l}$ reactions contained $1 \mu \mathrm{M}$ each primer, $1 \mathrm{X}$ PerfeCTa SYBR Green Super Mix (Quanta Biosciences), and 20 ng of cDNA. Experimental samples were amplified in parallel with serially diluted standards that were generated by PCR of cDNA using the indicated primers, followed by purification and quantitation by UV absorbance. Results from samples were compared relative to the standard curve to calculate copy number in each sample. Total TREM2 expression was the sum of the copy numbers for TREM2 exon 2 present and exon 2 skipped. Assays were performed in duplicate and normalized to expression of lba1 (AIF1) as the housekeeping gene, as TREM2 in the CNS is exclusively expressed in microglia. 
For cross-tissue comparison, the percent exon 2 skipping was calculated by dividing the exon 2 skipped copies by the sum of the exon 2 skipped and mean of exon 2 present copies without normalization. Data in the cross-tissue comparison reflect six technical replicates.

\section{TREM2 transcript cloning}

The full-length TREM2 and D2-TREM2 transcripts were amplified from gel extracts as above and genomic DNA was amplified using the same primers as above. Amplification was performed with Platinum Taq (Invitrogen 10966034) with the following cycling parameters: 2 min at $94^{\circ} \mathrm{C} ; 30 \mathrm{~s}$ at $94^{\circ} \mathrm{C}, 30 \mathrm{~s}$ at $60^{\circ} \mathrm{C}, 2 \mathrm{~min}$ at $72^{\circ} \mathrm{C}, 30$ cycles; $7 \mathrm{~min}$ at $72^{\circ} \mathrm{C}, 25^{\circ} \mathrm{C}$ hold. All cloning was performed using a pcDNA 3.1-V5/His TOPO-TA cloning kit (Invitrogen K480001) per manufacturer's instructions. Clones were verified by sequencing (ACGT; Wheeling, IL) and grown for midi-scale production and purification using a Qiagen Plasmid Plus Midiprep kit (Qiagen 12943).

\section{HMC3 Transfection}

HMC3 human microglia were transfected with Lipofectamine 3000 with Plus reagent (Invitrogen L3000001) per manufacturer instructions with $0.8 \mu \mathrm{L}$ of Lipofectamine 3000, $1 \mu \mathrm{L}$ Plus reagent, and $250 \mathrm{ng}$ plasmid per well in 8 well glass chamber slides (MatTek CCS-8). Cells were incubated for 24 hours prior to processing for microscopy.

\section{Confocal Immunofluorescence Microscopy}

Transfected HMC3 cells were fixed with 10\% neutral buffered formalin (Fisher Scientific SF100-4) for 30 minutes then blocked and permeabilized for 30 minutes with $10 \%$ goat serum (Sigma S26-LITER), 0.1\% Triton X-100 (Fisher Scientific BP151-500) in PBS (Fisher BioReagents BP665-1). Primary and secondary antibodies were diluted in the same blocking and permeabilization buffer and incubated at room temperature for 90 minutes. Cells were washed three times in blocking and permeabilization buffer between primary and secondary 
antibodies, and three times in PBS prior to coverslip mounting with Prolong Glass with NucBlue mounting media (Invitrogen P36981) and high-tolerance No. 1.5 coverglass (ThorLabs CG15KH1). Images were acquired using a Nikon A1R HD inverted confocal microscope with a 60X oil objective and NIS Elements AR software.

\section{Statistical Analyses}

Analyses were performed using GraphPad Prism 8.4.2. Quantitative data were first checked for normality by the D’Agostino \& Pearson test. Normally distributed data were analyzed using a two-tailed t-test, while data not normally distributed were analyzed with a twotailed Mann Whitney test and are noted along with $\mathrm{p}$ values.

\section{Results}

TREM2 undergoes extensive alternative splicing in human adult brain

To fully characterize TREM2 alternative splicing, we PCR-amplified TREM2 cDNA from anterior cingulate cortex by using primers corresponding to sequences within exons 1 and 5 . A gene map, including introns and encoded protein domains, is shown with forward and reverse primers (Figure 1, top). We observed substantial alternative splicing in both $A D$ and non-AD individuals (Figure 1, left). The identity of each isoform was confirmed by direct sequencing (Figure 1, right). This effort identified multiple novel TREM2 isoforms that have not been reported previously, including isoforms with multiple exons skipped.

Since this assay suggested that the the isoform lacking exon 2 (D2-TREM2) is the most abundance variant, we next quantified TREM2 and this alternate D2-TREM2 isoform in a series of brain samples. Since TREM2 is almost exclusively expressed by microglia in the brain, we normalized the TREM2 copy number to that of AIF1 (Figure 2A). While we do observe a trend 
toward higher TREM2 in the AD group, this difference is not significant $(p=0.1268$, two-tailed ttest). We next investigated whether D2-TREM2 occurred more frequently in AD vs. non-AD individuals. We found that exon 2 skipping correlates well with total TREM2 expression (Figure 2B), but observed no difference in exon 2 skipping frequency between the two groups (Figure 2C; $p=0.4909$, Mann Whitney test).

TREM2 alternative splicing is conserved across tissues

To test whether the observed alternative splicing is specific to brain, we subjected cDNA libraries from aorta, lung, kidney, heart, skeletal muscle, brain, and liver to PCR amplification with primers in TREM2 exons 1 and 5, as described above (Figure 1). We observed each of the previous splice isoforms across multiple tissues, though each isoform was not present in all tissues (Figure 3). We also observed a high relative abundance of the isoform lacking both exon 2 and 3 along with the isoform lacking exons 2 and 4 . This may reflect PCR bias, where shorter fragments are amplified more efficiently than longer fragments and are overrepresented in relative abundance. Nonetheless, the D2-TREM2 isoform was an abundant alternative isoform across all tissues surveyed. We then quantified TREM2 exon 2 skipping frequency in these samples and found similar frequency of exon 2 skipping across tissues (Figure 4).

\section{D2-TREM2 protein localizes similar to full-length TREM2}

To test whether the D2-TREM2 protein isoform is trafficked similarly to the full-length isoform, we cloned each isoform into expression vectors and transfected HMC3 human microglial cells for confocal microscopy (Figure 5). We observed similar staining patterns from both the FL-TREM2 (Figure 5A) and D2-TREM2 (Figure 5B), and this staining pattern is consistent with intracellular retention prevoiusly reported $[25,26]$. This implies the D2-TREM2 protein maintains the localization pattern of its parent full-length TREM2. We confirmed the D2- 
bioRxiv preprint doi: https://doi.org/10.1101/2021.11.23.469712; this version posted November 23, 2021. The copyright holder for this preprint (which was not certified by peer review) is the author/funder, who has granted bioRxiv a license to display the preprint in perpetuity. It is made available under aCC-BY-NC-ND 4.0 International license.

TREM2 isoform is predominantly retained in the Golgi complex (Figure $5 \mathrm{C}$ ) as has been previously reported for the FL-TREM2 and shown here (Figure 5D). 


\section{Discussion}

The primary findings of this report are that TREM2 undergoes far more extensive alternative splicing than has been previously reported [20-22, 24], that D2-TREM2 is a common variant that is not influenced by AD neuropathology, and that D2-TREM2 co-localizes with fulllength TREM2. As such, this comprehensive analysis of TREM2 alternative splicing extends prior knowledge, noting that Ensembl lists only full-length TREM2 (ENST00000373113.8), exon 4 skipped (D4-TREM2; ENST00000338469.3), and intron 3 retained isoforms (ENST00000373122.8) as known transcripts; NCBI only lists the full length (NM_018965.4) and D4-TREM2 (NM_001271821.2). Exon 3 skipping has been previously described in two small cohorts [3, 22]. The D2-TREM2 isoform is not annotated in either the NCBI nor Ensembl database. The D2-TREM2 isoform in brain was recently reported [24, 27], and our brain quantitation data closely replicate their results (Figure $2 \mathrm{C}$ ). In addition, we demonstrate that this splice isoform is expressed across multiple tissues (Figure 3) with roughly equal relative abundance (Figure 4). We further extend these recent findings by demonstrating that isoforms exist with multiple exons skipped, such that all permutations of exons 2, 3, and 4 can be skipped individually or in combination (Figure 1), and that exon 2 skipping frequency is not different as a function of $A D$ neuropathology.

While TREM2 has well-described cell surface localization including receptor activity [12$14,17]$, interactions with DAP12 [28], and proteolytic cleavage by ADAM10 [29, 30], there also exists a considerable intracellular TREM2 pool [25, 26]. Our localization studies support the hypothesis that D2-TREM2 localizes to the same compartment as FL-TREM2. Both appear to be predominantly localized to the Golgi complex (Figure 5C-D), replicating previous work with FL-TREM2 [25, 26]. The recent D2-TREM2 report [24] provided evidence of membrane-bound D2-TREM2 and FL-TREM2 by Western blots on subcellular fractions. Taken together, this suggests that TREM2_-and likely D2-TREM2_resides in a transmembrane Golgi pool. 
Functionally, TREM2 seems to operate under a feed-forward mechanism which D2TREM2 may act to inhibit. Experiments in vitro suggest that the transmembrane Golgi pool rapidly moves to the cell membrane in response to intracellular calcium flux induced by ionomycin $[25,26]$. Ligation of TREM2 using monoclonal antibodies also elicits an intracellular calcium spike. Whether D2-TREM2 inhibits this feed-forward mechanism, where TREM2 signaling induces calcium flux and increases cell surface mobilization, is still unknown.

TREM2 variants were some of the first genetic risk factors outside of APOE4 identified for LOAD [1, 2], have been replicated in multiple GWAS [4-7], and have the highest odds ratios for LOAD after APOE4 [31]. Variants encoding the p.R47H (rs75932628) and p.R62H (rs143332484) disrupt ligand binding and are predicted to be partial loss-of-function mutations [8-11]. We hypothesize that the D2-TREM2 protein is a functionally null receptor, as the ligand binding IgV domain is missing (Figure 1), though this has yet to be confirmed. In a similar case, $C D 33$ has an isoform with relatively high abundance that is also lacking its ligand binding lgV domain (D2-CD33); however genetics [32], mouse models [33], and in vitro studies with human pluripotent stem cell-derived microglia [34, 35] suggest the D2-CD33 protein may have a gain of function which acts independent of its loss of receptor activity.

TREM2 remains a promising target in potential AD therapeutics, evidenced by the strong interest in preclinical TREM2 monoclonal antibody treatments including a Phase 2 trial of AL002a (Alector, NCT04592874). Modulation of alternative splice isoforms of TREM2 may represent a novel therapeutic pathway. The previously reported D4-TREM2 isoform lacks a transmembrane domain (Figure 1) and is likely secreted as soluble TREM2 (sTREM2) which may be AD-protective [36, 37]. We posit that the D2-TREM2 isoform acts similarly to the p. $\mathrm{R} 47 \mathrm{H}$ and p. $\mathrm{R} 62 \mathrm{H}$ variants by reducing TREM2 function, and balanced with D4-TREM2, this forms a potentially druggable rheostat. Early in the disease, increased TREM2 function and sTREM2 secretion are apparently beneficial; increasing full-length TREM2 would promote 
functional TREM2 signaling and increased D4-TREM2 would promote increased sTREM2 secretion. Later in disease when inflammation may be detrimental, increasing D2-TREM2 could provide a switch to decrease TREM2 activity and inflammation (Figure 6).

We note one outlying point in our quantitation data (Figure 2C, AD subject, top) with substantially higher D2-TREM2 than the rest of our subjects. This subject may have an underlying genetic variant which regulates exon 2 skipping in cis, and current work seeks to better understand this outlier. Future studies will examine in greater depth using RNA sequencing methods whether this splice isoform is associated with any genetic variants, such as the p. $\mathrm{R} 47 \mathrm{H}$ and $\mathrm{p} . \mathrm{R} 62 \mathrm{H}$ variants or other rare mutations. 


\section{Acknowledgements}

This work was supported by F99NS120365 (BCS), RF1AG059717 (SE), and R21AG068370 (SE). We would like to thank the Sanders-Brown Center on Aging Biorepository for samples, supported by P30AG072946.

\section{Authorship Contributions}

Benjamin C. Shaw: Conceptualization, Methodology, Software, Validation, Formal Analysis, Investigation, Data Curation, Writing - Original Draft, Writing - Review \& Editing, Visualization, Supervision, Funding Acquisition. Henry C. Snider: Conceptualization, Validation, Investigation, Writing - Review \& Editing, Visualization. Andrew K. Turner: Investigation, Writing - Review \& Editing, Visualization. Diana J. Zajac: Validation, Investigation, Writing Review \& Editing, Visualization. James F. Simpson: Conceptualization, Methodology, Software, Validation, Formal Analysis, Investigation, Data Curation, Writing - Review \& Editing, Visualization. Steven Estus: Conceptualization, Methodology, Software, Validation, Formal Analysis, Resources, Data Curation, Writing - Review \& Editing, Visualization, Supervision, Project Administration, Funding Acquisition.

\section{Disclosure of Conflicts of Interest}

Authors declare no conflicts of interest. 


\section{References}

[1] Jonsson T, Stefansson H, Steinberg S, Jonsdottir I, Jonsson PV, Snaedal J, et al. Variant of TREM2 Associated with the Risk of Alzheimer's Disease. New England Journal of Medicine. 2013;368:107-16.

[2] Guerreiro R, Wojtas A, Bras J, Carrasquillo M, Rogaeva E, Majounie E, et al. TREM2 variants in Alzheimer's disease. N Engl J Med. 2013;368:117-27.

[3] Paloneva J, Manninen T, Christman G, Hovanes K, Mandelin J, Adolfsson R, et al. Mutations in Two Genes Encoding Different Subunits of a Receptor Signaling Complex Result in an Identical Disease Phenotype. The American Journal of Human Genetics. 2002;71:656-62.

[4] Kunkle BW, Grenier-Boley B, Sims R, Bis JC, Damotte V, Naj AC, et al. Genetic metaanalysis of diagnosed Alzheimer's disease identifies new risk loci and implicates Abeta, tau, immunity and lipid processing. Nat Genet. 2019;51:414-30.

[5] Lambert JC, Ibrahim-Verbaas CA, Harold D, Naj AC, Sims R, Bellenguez C, et al. Metaanalysis of 74,046 individuals identifies 11 new susceptibility loci for Alzheimer's disease. Nat Genet. 2013;45:1452-8.

[6] Jansen IE, Savage JE, Watanabe K, Bryois J, Williams DM, Steinberg S, et al. Genome-wide meta-analysis identifies new loci and functional pathways influencing Alzheimer's disease risk. Nat Genet. 2019.

[7] Wightman DP, Jansen IE, Savage JE, Shadrin AA, Bahrami S, Holland D, et al. A genomewide association study with 1,126,563 individuals identifies new risk loci for Alzheimer's disease. Nature Genetics. 2021;53:1276-82.

[8] Dean HB, Roberson ED, Song Y. Neurodegenerative Disease-Associated Variants in TREM2 Destabilize the Apical Ligand-Binding Region of the Immunoglobulin Domain. Frontiers in Neurology. 2019;10. 
[9] Gratuze M, Leyns CEG, Sauerbeck AD, St-Pierre M-K, Xiong M, Kim N, et al. Impact of TREM2R47H variant on tau pathology-induced gliosis and neurodegeneration. Journal of Clinical Investigation. 2020;130:4954-68.

[10] Piers TM, Cosker K, Mallach A, Johnson GT, Guerreiro R, Hardy J, et al. A locked immunometabolic switch underlies TREM2 R47H loss of function in human iPSC-derived microglia. The FASEB Journal. 2020;34:2436-50.

[11] Cosker K, Mallach A, Limaye J, Piers TM, Staddon J, Neame SJ, et al. Microglial signalling pathway deficits associated with the patient derived R47H TREM2 variants linked to AD indicate inability to activate inflammasome. Scientific Reports. 2021;11.

[12] Atagi Y, Liu C-C, Painter MM, Chen X-F, Verbeeck $C$, Zheng H, et al. Apolipoprotein E Is a Ligand for Triggering Receptor Expressed on Myeloid Cells 2 (TREM2). Journal of Biological Chemistry. 2015;290:26043-50.

[13] Zhao Y, Wu X, Li X, Jiang L-L, Gui X, Liu Y, et al. TREM2 Is a Receptor for $\beta$-Amyloid that Mediates Microglial Function. Neuron. 2018;97:1023-31.e7.

[14] McQuade A, Kang YJ, Hasselmann J, Jairaman A, Sotelo A, Coburn M, et al. Gene expression and functional deficits underlie TREM2-knockout microglia responses in human models of Alzheimer's disease. Nature Communications. 2020;11.

[15] Holtman IR, Raj DD, Miller JA, Schaafsma W, Yin Z, Brouwer N, et al. Induction of a common microglia gene expression signature by aging and neurodegenerative conditions: a coexpression meta-analysis. Acta Neuropathologica Communications. 2015;3.

[16] Keren-Shaul H, Spinrad A, Weiner A, Matcovitch-Natan O, Dvir-Szternfeld R, Ulland TK, et al. A Unique Microglia Type Associated with Restricting Development of Alzheimer's Disease. Cell. 2017;169:1276-90 e17.

[17] Griciuc A, Patel S, Federico AN, Choi SH, Innes BJ, Oram MK, et al. TREM2 Acts Downstream of CD33 in Modulating Microglial Pathology in Alzheimer's Disease. Neuron. 2019;103:820-35 e7. 
[18] Wang Y, Cella M, Mallinson K, Jason, Katherine, Michelle, et al. TREM2 Lipid Sensing Sustains the Microglial Response in an Alzheimer's Disease Model. Cell. 2015;160:1061-71.

[19] Jay TR, Miller CM, Cheng PJ, Graham LC, Bemiller S, Broihier ML, et al. TREM2 deficiency eliminates TREM2+ inflammatory macrophages and ameliorates pathology in Alzheimer's disease mouse models. Journal of Experimental Medicine. 2015;212:287-95.

[20] Del-Aguila JL, Benitez BA, Li Z, Dube U, Mihindukulasuriya KA, Budde JP, et al. TREM2 brain transcript-specific studies in $A D$ and TREM2 mutation carriers. Molecular Neurodegeneration. 2019;14.

[21] Yanaizu M, Sakai K, Tosaki Y, Kino Y, Satoh J-i. Small nuclear RNA-mediated modulation of splicing reveals a therapeutic strategy for a TREM2 mutation and its post-transcriptional regulation. Scientific Reports. 2018;8:6937.

[22] Numasawa Y, Yamaura C, Ishihara S, Shintani S, Yamazaki M, Tabunoki H, et al. NasuHakola disease with a splicing mutation of TREM2 in a Japanese family. European Journal of Neurology. 2011;18:1179-83.

[23] Finkel RS, Mercuri E, Darras BT, Connolly AM, Kuntz NL, Kirschner J, et al. Nusinersen versus Sham Control in Infantile-Onset Spinal Muscular Atrophy. New England Journal of Medicine. 2017;377:1723-32.

[24] Kiianitsa K, Kurtz I, Beeman N, Matsushita M, Chien W-M, Raskind WH, et al. Novel TREM2 splicing isoform that lacks the V-set immunoglobulin domain is abundant in the human brain. Journal of Leukocyte Biology. 2021;1.

[25] Sessa G, Podini P, Mariani M, Meroni A, Spreafico R, Sinigaglia F, et al. Distribution and signaling of TREM2/DAP12, the receptor system mutated in human polycystic lipomembraneous osteodysplasia with sclerosing leukoencephalopathy dementia. European Journal of Neuroscience. 2004;20:2617-28. 
[26] Prada I, Ongania GN, Buonsanti C, Panina-Bordignon P, Meldolesi J. Triggering receptor expressed in myeloid cells 2 (TREM2) trafficking in microglial cells: Continuous shuttling to and from the plasma membrane regulated by cell stimulation. Neuroscience. 2006;140:1139-48.

[27] Han S, Na Y, Koh I, Nho K, Lee Y. Alternative Splicing Regulation of Low-Frequency Genetic Variants in Exon 2 of TREM2 in Alzheimer's Disease by Splicing-Based Aggregation. International Journal of Molecular Sciences. 2021;22:9865.

[28] Peng Q, Malhotra S, Torchia JA, Kerr WG, Coggeshall KM, Humphrey MB. TREM2- and DAP12-dependent activation of PI3K requires DAP10 and is inhibited by SHIP1. Sci Signal. 2010;3:ra38.

[29] Schlepckow K, Kleinberger G, Fukumori A, Feederle R, Lichtenthaler SF, Steiner H, et al. An Alzheimer-associated TREM2 variant occurs at the ADAM cleavage site and affects shedding and phagocytic function. EMBO Molecular Medicine. 2017;9:1356-65.

[30] Zhong L, Chen X-F, Zhang Z-L, Wang Z, Shi X-Z, Xu K, et al. DAP12 Stabilizes the Cterminal Fragment of the Triggering Receptor Expressed on Myeloid Cells-2 (TREM2) and Protects against LPS-induced Pro-inflammatory Response. Journal of Biological Chemistry. 2015;290:15866-77.

[31] Karch CM, Goate AM. Alzheimer's disease risk genes and mechanisms of disease pathogenesis. Biol Psychiatry. 2015;77:43-51.

[32] Estus S, Shaw BC, Devanney N, Katsumata Y, Press EE, Fardo DW. Evaluation of CD33 as a genetic risk factor for Alzheimer's disease. Acta Neuropathol. 2019.

[33] Bhattacherjee A, Jung SJ, Ho M, Eskandari-Sedighi G, St. Laurent CD, McCord KA, et al. The CD33 short isoform is a gain-of-function variant that enhances $A \beta 1-42$ phagocytosis in microglia. Molecular Neurodegeneration. 2021.

[34] Wißfeld J, Mathews M, Mossad O, Picardi P, Cinti A, Redaelli L, et al. Reporter cell assay for human CD33 validated by specific antibodies and human iPSC-derived microglia. Scientific Reports. 2021;11. 
[35] Wißfeld J, Nozaki I, Mathews M, Raschka T, Ebeling C, Hornung V, et al. Deletion of Alzheimer's disease-associated CD33 results in an inflammatory human microglia phenotype. Glia. 2021.

[36] Ewers M, Biechele G, Suárez-Calvet M, Sacher C, Blume T, Morenas-Rodriguez E, et al. Higher CSF sTREM2 and microglia activation are associated with slower rates of beta-amyloid accumulation. EMBO Molecular Medicine. 2020;12.

[37] Zhong L, Xu Y, Zhuo R, Wang T, Wang K, Huang R, et al. Soluble TREM2 ameliorates pathological phenotypes by modulating microglial functions in an Alzheimer's disease model. Nature Communications. 2019;10.

[38] Zou F, Gopalraj RK, Lok J, Zhu H, Ling IF, Simpson JF, et al. Sex-dependent association of a common low-density lipoprotein receptor polymorphism with RNA splicing efficiency in the brain and Alzheimer's disease. Human Molecular Genetics. 2007;17:929-35.

[39] Burchett ME, Ling IF, Estus S. FBN1 isoform expression varies in a tissue and development-specific fashion. Biochemical and Biophysical Research Communications. 2011;411:323-8. 


\section{Figure Legends}

Figure 1: TREM2 undergoes extensive alternative splicing. Top: a schematic of the TREM2 gene is shown with introns and exons. Approximate locations of the forward (green) and reverse (red) primers are shown. Left: a representative image of the PCR amplification and gel electrophoresis of TREM2 cDNA from $A D$ and non-AD brains. No differences in splicing patterns were noticed between $A D$ and non-AD; see Supplemental Figure 1 for full gel image with more samples. Right: schematic of the splice isoforms identified after sequencing. Colors correspond to exons in the gene model, while frameshifts are shown in grey. A doublet appears in the lower transcripts on the gel in which the lower band corresponds to CES3 in addition to the identified TREM2 isoforms. All bands identified in Figure 1 have been confirmed by Sanger sequencing.

Figure 2: Quantification of TREM2 and exon 2 skipping in human brain tissue. (A): Total TREM2 expression normalized to the microglial marker AIF1 expression. TREM2 expression is not significantly different between $A D$ and non-AD samples ( $p=0.1268$, t-test). (B) Expression of the isoform lacking exon 2 correlates well with expression of the isoform containing exon 2. (C) Exon 2 is skipped at an approximate frequency of $11 \%$, with no significant difference between AD vs. non-AD ( $p=0.4909$, Mann-Whitney test).

Figure 3: Complex patterns of TREM2 alternative splicing are present in many tissues. Human fetal cDNA libraries from multiple tissues were amplified using the same primers from Figure 1. The splice variants from Figure 1 are replicated across these six additional tissues. Differences in the relative abundance of each splice variant may be due to differences in developmental stage and/or splicing factor differences between tissues. 
Figure 4: Quantification of TREM2 and exon 2 skipping across tissues. Exon 2 is skipped at a frequency between 5.30 - 13.0\%. Data points reflect technical, not biological, replicates from pooled cDNA libraries.

Figure 5: TREM2 and D2-TREM2 have a similar subcellular localization. The HMC3 human microglial cell line was transfected with vectors encoding either full-length TREM2 $(A, C)$ or D2TREM2 (B,D). Both vectors have an in-frame V5 epitope tag. In $A$ and $B$, cells were subsequently labeled with antibodies against a TREM2 epitope encoded by exon 2 (red) or V5 (green). The limited red fluorescent labeling and absence of yellow overlap in the D2-TREM2 transfected cells $(B)$ is due to low endogenous TREM2 expression. In $C$ and $D$, transfected cells were labeled with antibodies against the Golgi complex marker GM130 (red) and V5 (green). The intracellular pools of both TREM2 (C) and D2-TREM2 (D) largely colocalize with GM130. Views represent the $X Y$ (main), $X Z$ (bottom) and $Y Z$ (right) views in each panel.

Figure 6: Model to exploit alternative splicing in TREM2 as a potential AD therapeutic. Early in disease when $A \beta$ pathology is developing, animal models suggest TREM2 signaling is protective. Hence, decreasing D2-TREM2 and increasing full-length TREM2 may be helpful in this stage of the disease (Left). Animal models also indicate TREM2 deficiency is protective from tau-related pathology suggesting a detrimental role for TREM2 signaling in this later stage of the disease when hyperphosphorylated tau accumulates. At this point, increased skipping of exon 2 to promote the "dead receptor" D2-TREM2 and thereby inhibit TREM2 signaling may be helpful (Right). 
bioRxiv preprint doi: https://doi.org/10.1101/2021.1123.469712. this version posted November 23, 2021. The copyright holder for this preprint (which was not certified by peer review) is the author/funder, who has granted bioRxiv a license to display the preprint in perpetuity. It is made available under aCC-BY-NC-ND 4.0 International license.

\section{Figures}

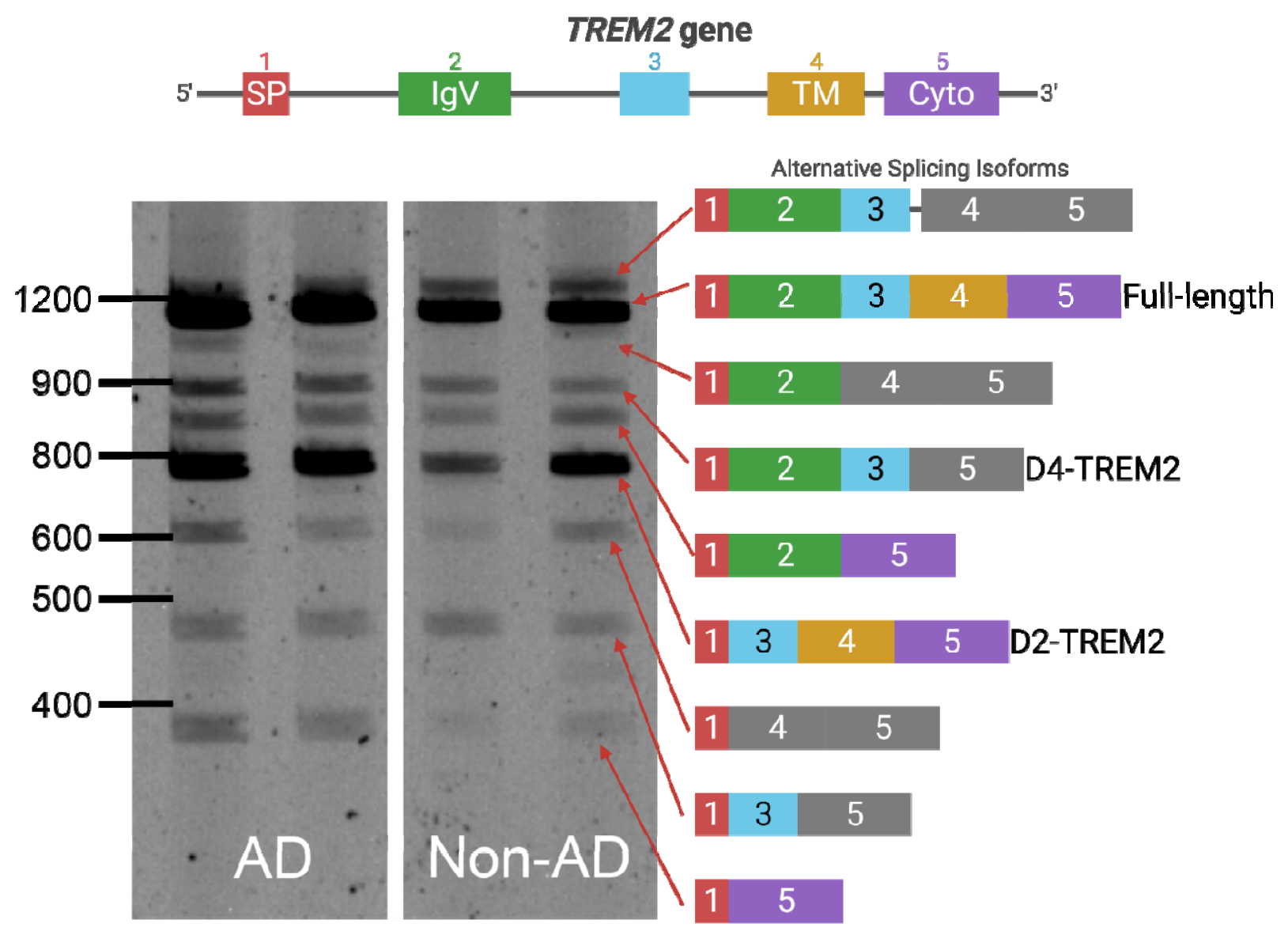

Figure 1: TREM2 undergoes extensive alternative splicing. 

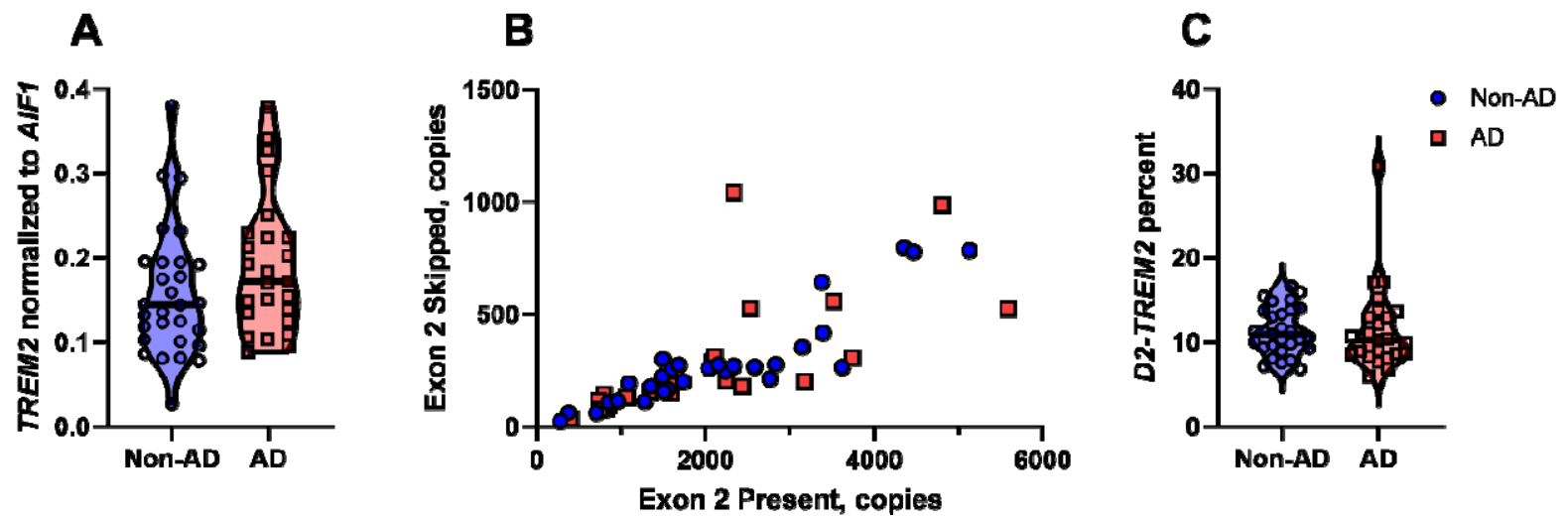

Figure 2: Quantification of TREM2 and exon 2 skipping in human brain tissue. 
bioRxiv preprint doi: https://doi.org/10.1101/2021.11.23.469712. this version posted November 23, 2021. The copyright holder for this preprint (which was not certified by peer review) is the author/funder, who has granted bioRxiv a license to display the preprint in perpetuity. It is made available under aCC-BY-NC-ND 4.0 International license.

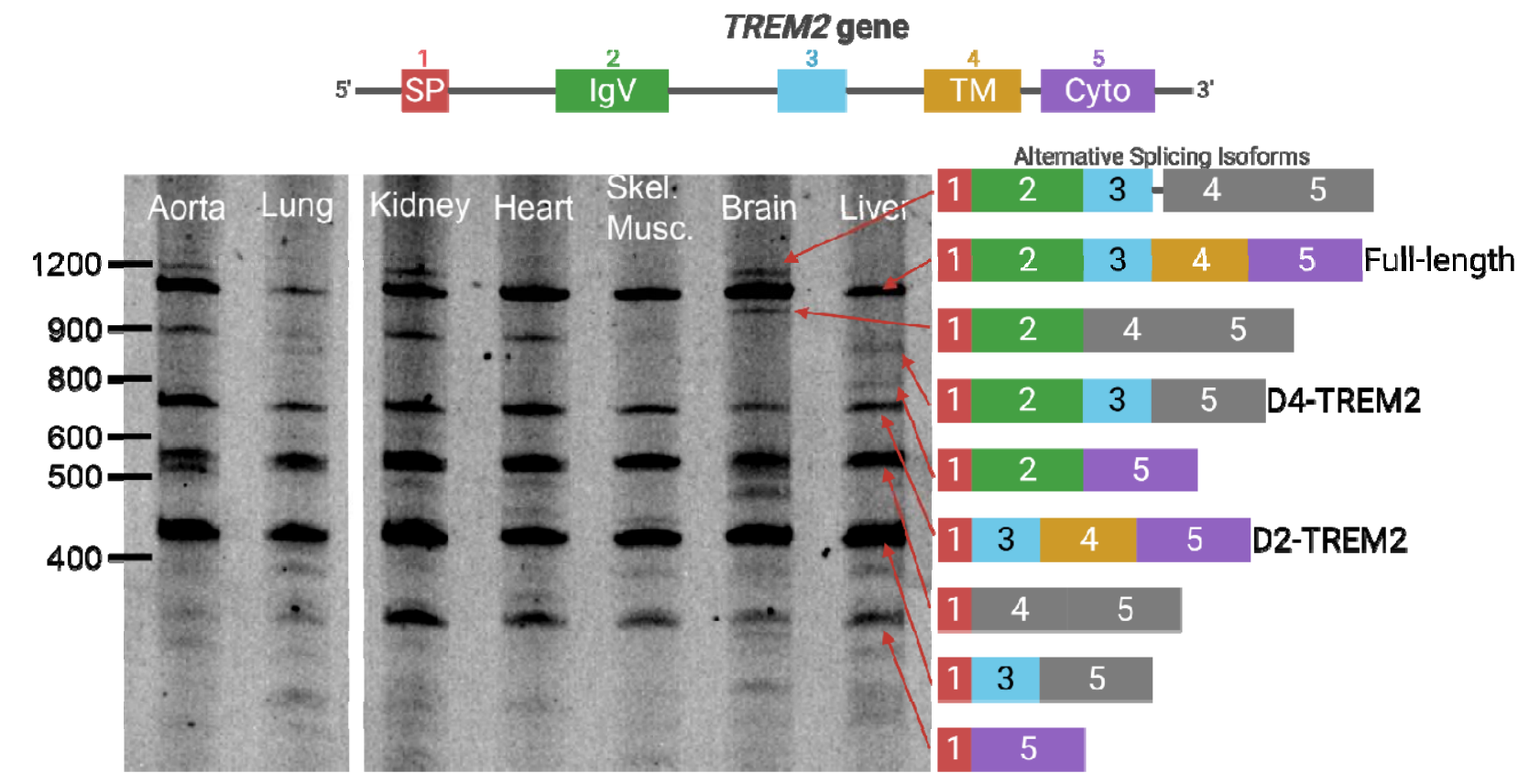

Figure 3: Complex patterns of TREM2 alternative splicing are present in many tissues. 
bioRxiv preprint doi: https://doi.org/10.1101/2021.1123.469712; this version posted November 23, 2021. The copyright holder for this preprint (which was not certified by peer review) is the author/funder, who has granted bioRxiv a license to display the preprint in perpetuity. It is made available under aCC-BY-NC-ND 4.0 International license.

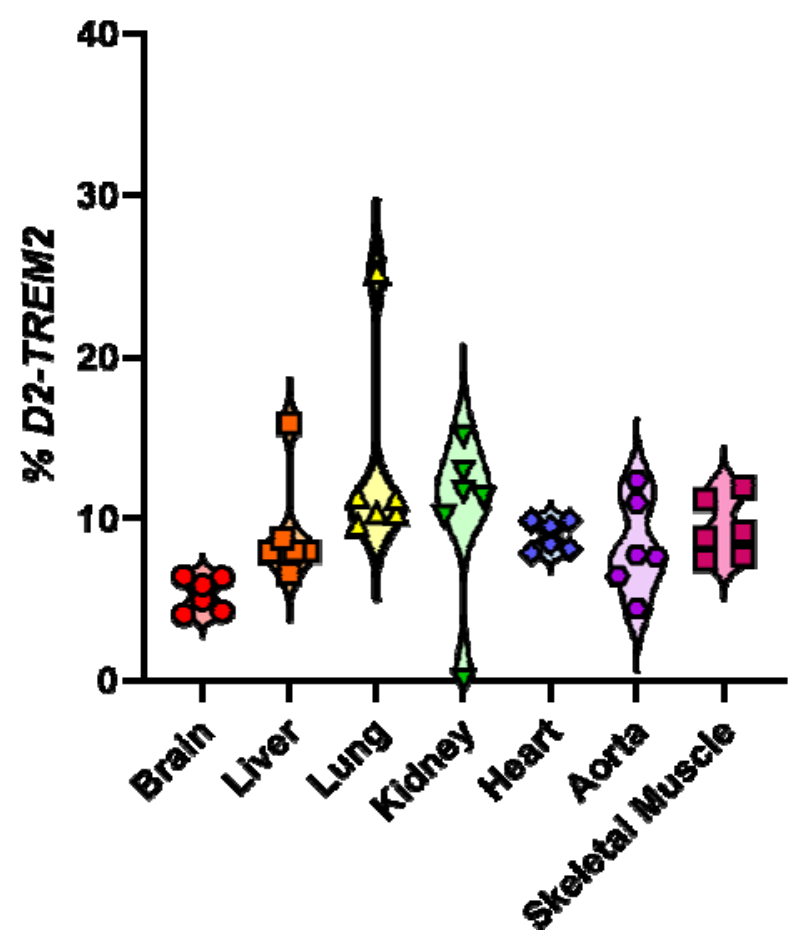

Figure 4: Quantification of TREM2 and exon 2 skipping across tissues. 
bioRxiv preprint doi: https://doi.org/10.1101/2021.11.23.469712; this version posted November 23, 2021. The copyright holder for this preprint (which was not certified by peer review) is the author/funder, who has granted bioRxiv a license to display the preprint in perpetuity. It is made available under aCC-BY-NC-ND 4.0 International license.

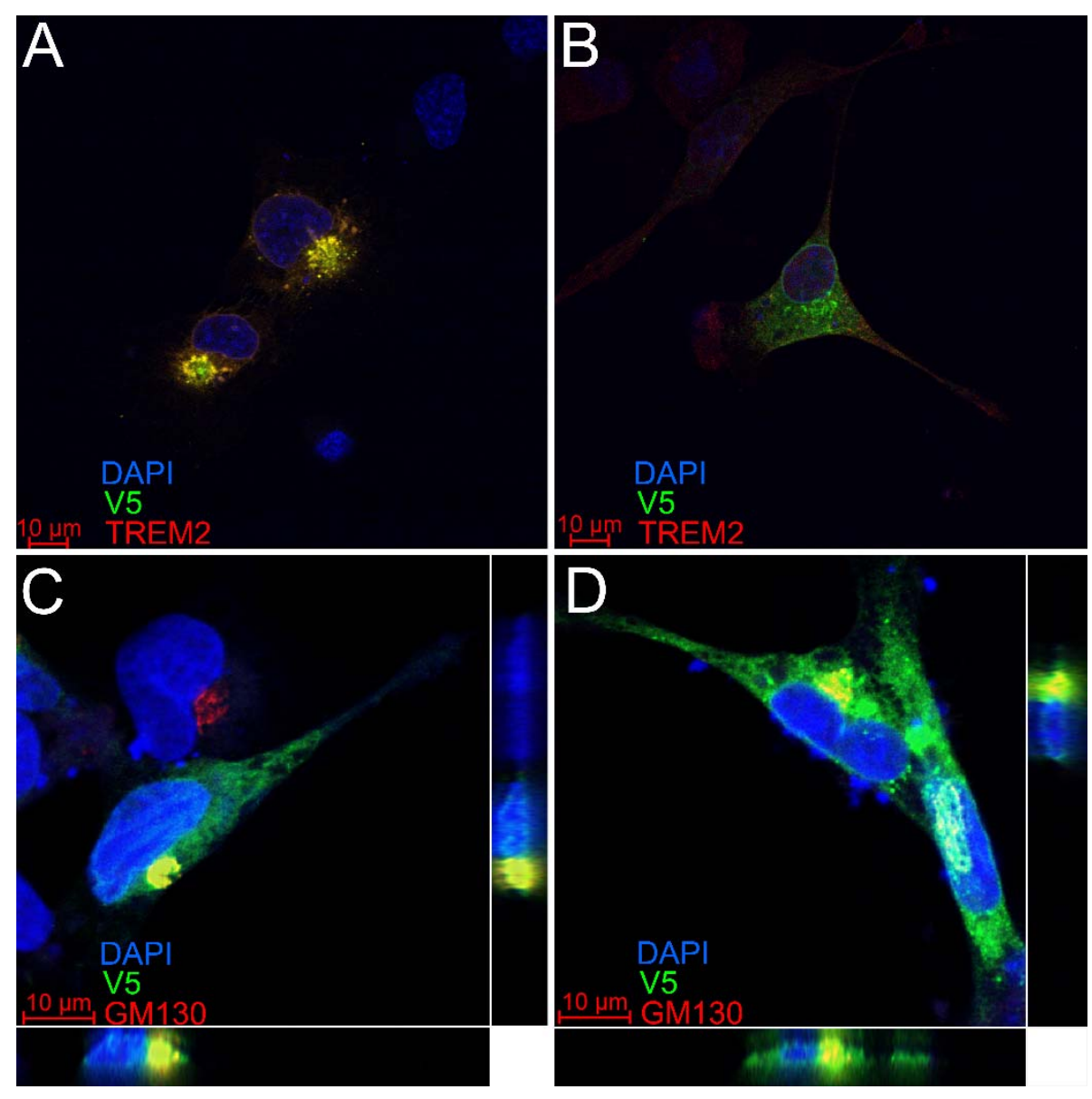

Figure 5: TREM2 and D2-TREM2 have similar subcellular localization. 


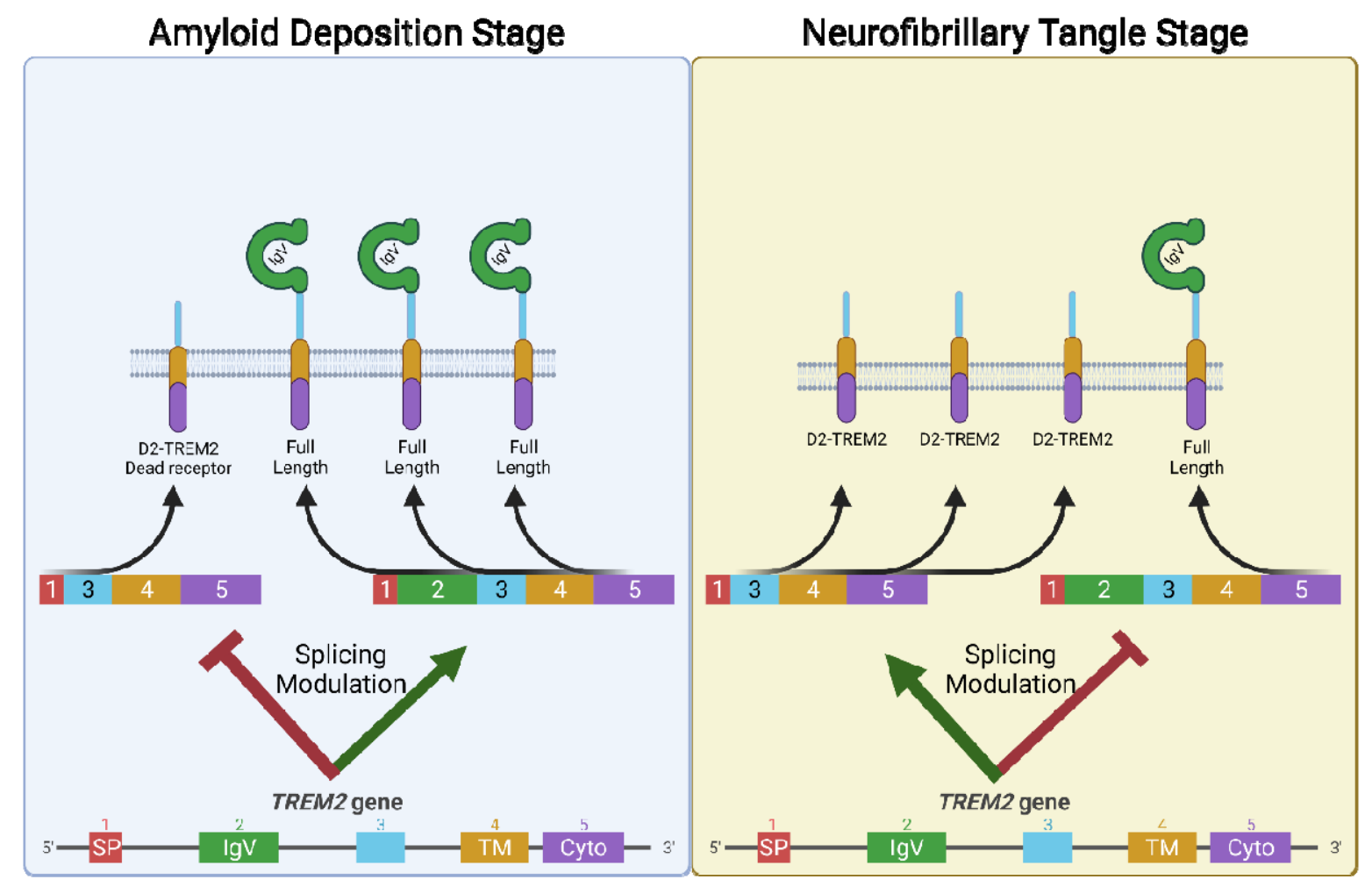

Figure 6: Model to exploit alternative splicing in TREM2 as a potential AD therapeutic. 
$\frac{1}{1}$

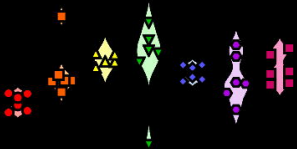




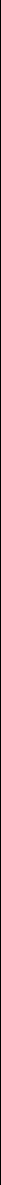


TREM2 gene

$5-\frac{1}{S P}$
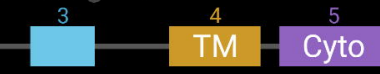

Alternative Splicing Isoforms

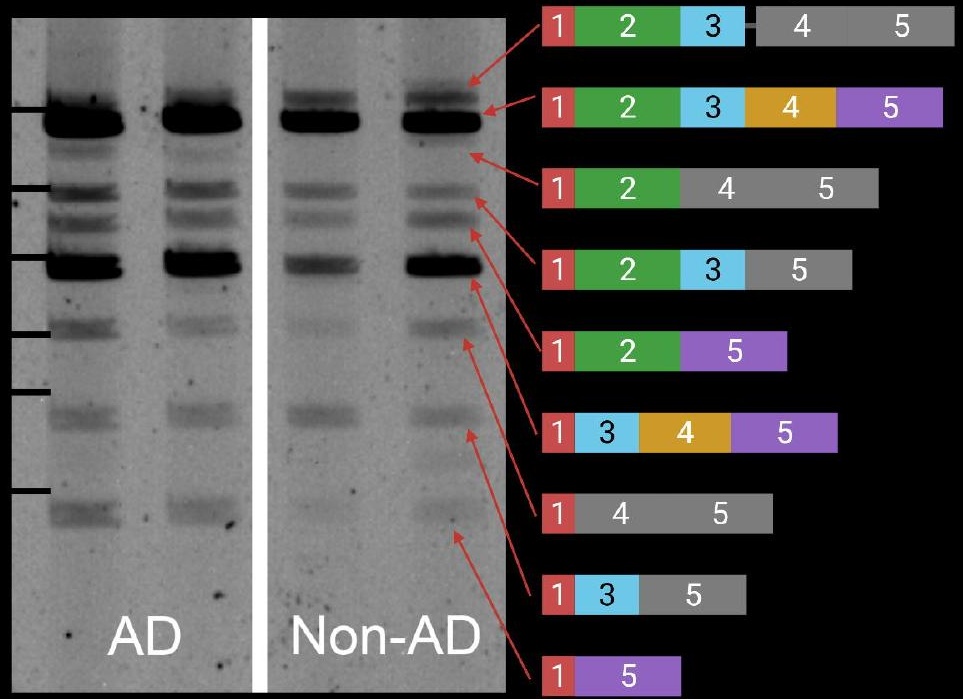



Alternative Splicing Isoforms

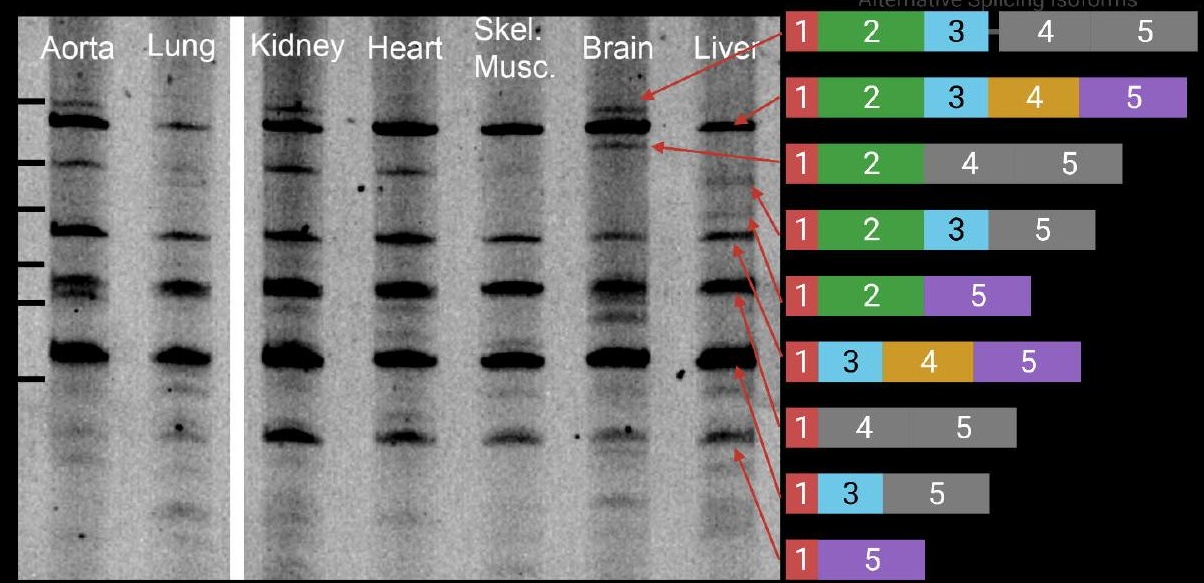

